\title{
Correction to: A unified method of defuzzification for type-2 fuzzy numbers with its application to multiobjective decision making
}

\author{
Animesh Biswas ${ }^{1}$ [D $\cdot$ Arnab Kumar De ${ }^{2}$
}

Published online: 2 March 2018

๑) Springer International Publishing AG, part of Springer Nature 2018

\section{Correction to: Granular Computing} https://doi.org/10.1007/s41066-017-0068-z

Unfortunately there were several typesetting mistakes in the original article.

In Section 2.6, fourth line, the lower membership function has to read $\underline{\mu}_{\tilde{A}}$. This was also incorrect in the following equation. The correct equation is:

Find $X\left(x_{1}, x_{2}, \ldots, x_{n}\right)$ so as to

Maximize $D V\left(\tilde{\tilde{Z}}_{k}\right)=\sum_{j=1}^{n} D V\left(\tilde{\tilde{c}}_{k j}\right) x_{j} ; \quad k=1,2, \ldots, K$

Subject to $\sum_{j=1}^{n} D V\left(\tilde{\tilde{a}}_{i j}\right) x_{j} \leqslant D V\left(\tilde{\tilde{b}}_{i}\right) ; \quad i=1,2, \ldots, m$

$x_{j} \geqslant 0$

$j=1,2, \ldots, n$ if $e \leqslant x \leqslant f$

if $f \leqslant x \leqslant g$

if $g \leqslant x \leqslant h$.

otherwise
In Table 2 the ranking values of Qin and Liu (2015) were incorrectly displayed. It is conformable with the previous presentations.

In Section 5.1, equation 5, the symbols "-." and " " were wrongly placed. The correct equation reads:
In equation 6, the first line is to be replaced by Find $\mathrm{X}\left(\mathrm{x} \_1, \mathrm{x} \_2, \ldots, \mathrm{x} \_\mathrm{n}\right)$ in place of $\mathrm{X}\left(\mathrm{x} \_1,-\mathrm{x} \_2,-, \ldots,-\mathrm{x} \_n\right)$. Also the sign ' $\sim$ ' is to be deleted after ' $\leq$ ' sign in fourth line of equation 6.

The original article can be found online at https://doi.org/10.1007/ s41066-017-0068-z.

Animesh Biswas

abiswaskln@ rediffmail.com

Arnab Kumar De

arnab7339@yahoo.co.in

1 Department of Mathematics, University of Kalyani,

Kalyani 741235, India

2 Department of Mathematics, Government College of Engineering and Textile Technology, Serampore 712201, India 